\title{
Fuzzy Distance of Trapezoidal Fuzzy Numbers
}

\author{
Shan-Huo Chen ${ }^{1}$ Chien-Chung Wang ${ }^{2}$ \\ ${ }^{1}$ Department of information Management, Ching Yun University,229, Chien-Hsin Rd.,Jung-Li,320 Taiwan. \\ Email: shchen_im@cyu.edu.tw \\ ${ }^{2}$ Department of Statistics, National Defense Management College, National Defense University, \\ 150, Ming-An St., Chung-Ho, 235, Taiwan. \\ Email: wangcc@rs590.ndmc.edu.tw
}

\begin{abstract}
Fuzzy distance is applied on data analysis, classification, and product positioning analysis widely. In this paper, We introduce a fuzzy distance by using graded mean integration representation of generalized fuzzy number and the span of fuzzy number, We also discuss the distance of the linguistic data of "greater or less than $\mathrm{x}$ " and "about $\mathrm{x}$ ". It is reasonable to say "the fuzzy distance of about 3 and about 7 is about 4 not 4."
\end{abstract}

Keywords: Fuzzy Number, Graded mean integration Representation, Fuzzy Distance, Distance.

\section{Introduction}

In most of cases in our life, the data obtained for decision making are only approximately known. In 1965, Zadeh [8] introduced the concept of fuzzy set theory to meet those problems. In 1978, Dubois and Prade defined any of the fuzzy numbers as a fuzzy subset of the real line. Fuzzy numbers allow us to make the mathematical model of linguistic variable or fuzzy environment.

In 1992, Liu [7] discussed three concepts of distance measures (normal distance, -distance, sub-distance) of fuzzy sets.

In 1991, Kaufmann et al. [6] considered a distance measure of two fuzzy numbers combined by the interval of $\alpha$-cuts of fuzzy numbers. In 1997, Heilpern [5] proposed three definitions of the distance between two fuzzy numbers. These include that mean distance method is generated by expect values of fuzzy numbers, distance method is combined by a Minkowski distance and the h-levels of the closed intervals of fuzzy numbers, and geometrical distance method is based on the geometrical operation of trapezoidal fuzzy numbers All of them use real number to calculate the distance. In this paper, the fuzzy distance between two trapezoidal fuzzy numbers is measured by using graded mean integration representation $[2,3,4]$ and the span of fuzzy number.

\section{Representation of generalized fuzzy number}

In general, a generalized fuzzy number A is described as any fuzzy subset of the real line $\mathrm{R}$, whose membership function $\mu_{\mathrm{A}}$ satisfies the following conditions.

(1) $\mu_{\mathrm{A}}$ is a continuous mapping from $\mathrm{R}$ to the closed interval $[0,1]$,

(2) $\mu_{\mathrm{A}}(\mathrm{x})=0,-\infty<\mathrm{x} \leq \mathrm{c}$,

(3) $\mu_{\mathrm{A}}(\mathrm{x})=\mathrm{L}(\mathrm{x})$ is strictly increasing on $[\mathrm{c}, \mathrm{a}]$,

(4) $\mu_{\mathrm{A}}(\mathrm{x})=\mathrm{w}, \mathrm{a} \leq \mathrm{x} \leq \mathrm{b}$,

(5) $\mu_{\mathrm{A}}(\mathrm{x})=\mathrm{R}(\mathrm{x})$ is strictly decreasing on [b, d],

(6) $\mu_{\mathrm{A}}(\mathrm{x})=0, d \leq \mathrm{x}<\infty$,

where $0<w \leq 1, a, b, c$, and $d$ are real numbers. We denote this type of generalized fuzzy number as $\mathrm{A}=(\mathrm{c}$, $\mathrm{a}, \mathrm{b}, \mathrm{d} ; \mathrm{w})_{\mathrm{LR}}$. When $\mathrm{w}=1$, we denote this type of generalized fuzzy number as $A=(c, a, b, d)_{L R}$. When $\mathrm{L}(\mathrm{x})$ and $\mathrm{R}(\mathrm{x})$ are straight line, Then $\mathrm{A}$ is a trapezoidal fuzzy number, we denote it as (c, a , b , d).

In 1998, Chen and Hsieh [2,3,4] propose graded mean integration representation for representing generalized fuzzy number. Now we describe graded mean integration representation (GMIR) as follows.

Suppose $\mathrm{L}^{-1}$ and $\mathrm{R}^{-1}$ are inverse functions of functions $\mathrm{L}$ and $\mathrm{R}$, respectively, and the graded mean $h$-level value of generalized fuzzy number $A=(c, a, b$, $\mathrm{d} ; \mathrm{w})_{\mathrm{LR}}$ is $\mathrm{h}\left[\mathrm{L}^{-1}(\mathrm{~h})+\mathrm{R}^{-1}(\mathrm{~h})\right] / 2$ as Figure 1 . Then the graded mean integration representation of generalized fuzzy number based on the integral value of graded mean h-levels is

$\mathrm{P}(\mathrm{A})=\int_{0}^{\mathrm{w}} \mathrm{h}\left(\frac{\mathrm{L}^{-1}(\mathrm{~h})+\mathrm{R}^{-1}(\mathrm{~h})}{2}\right) \mathrm{dh} / \int_{0}^{\mathrm{w}} \mathrm{h} \mathrm{dh}$,

where $\mathrm{h}$ is between 0 and $\mathrm{w}, 0<\mathrm{w} \leq 1$.

Generalized trapezoidal fuzzy number and generalized triangular fuzzy number are denoted as (c, $\mathrm{a}, \mathrm{b}, \mathrm{d} ; \mathrm{w})$ and (c, a, d; w) respectively. Chen and Hsieh $[2,3,4]$ already find the general formulae of the 


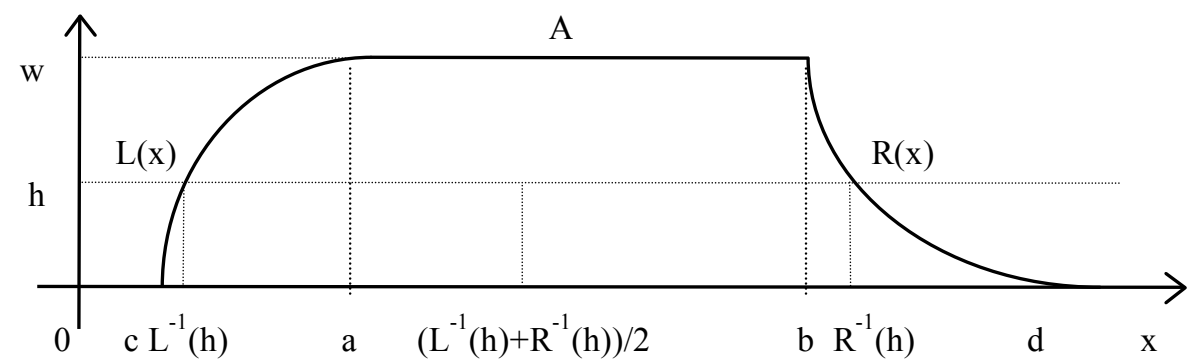

Fig. 1. The graded mean integration of a generalized fuzzy number $A=(c, a, b, d ; w)_{L R}$.

representation of generalized trapezoidal fuzzy number, or generalized triangular fuzzy number as follows.

Suppose $A=(c, a, b, d ; w)$ is a trapezoidal fuzzy number. Since,

$$
\mathrm{L}(\mathrm{x})=\mathrm{w}\left(\frac{\mathrm{x}-\mathrm{c}}{\mathrm{a}-\mathrm{c}}\right), \quad \mathrm{c} \leq \mathrm{x} \leq \mathrm{a},
$$

and $\mathrm{R}(\mathrm{x})=\mathrm{w}\left(\frac{\mathrm{x}-\mathrm{d}}{\mathrm{b}-\mathrm{d}}\right), \quad \mathrm{b} \leq \mathrm{x} \leq \mathrm{d}$,

then

$$
\mathrm{L}^{-1}(\mathrm{~h})=\mathrm{c}+(\mathrm{a}-\mathrm{c}) \mathrm{h} / \mathrm{w}, \quad 0 \leq \mathrm{h} \leq \mathrm{w},
$$$$
\mathrm{R}^{-1}(\mathrm{~h})=\mathrm{d}-(\mathrm{d}-\mathrm{b}) \mathrm{h} / \mathrm{w}, 0 \leq \mathrm{h} \leq \mathrm{w},
$$

and $\frac{L^{-1}(h)+R^{-1}(h)}{2}=\frac{c+d+(a-c-d+b) h / w}{2}$.

By formula (1), the graded mean integration representation of $\mathrm{A}$ is

$$
\begin{aligned}
P(A) & =\int_{0}^{w} h\left(\frac{c+d+(a-c-d+b) h / w}{2}\right) d h / \int_{0}^{w} h d h \\
= & \frac{c+2 a+2 b+d}{6} .
\end{aligned}
$$

Generalized triangular fuzzy number $\mathrm{Y}=(\mathrm{c}, \mathrm{a}, \mathrm{d}$; $w)$ is a special case of generalized trapezoidal fuzzy number when $b=a$. Then replacing $b$ by $a$ in formula (2), the graded mean integration representation of $\mathrm{Y}$ becomes

$$
\mathrm{P}(\mathrm{Y})=\frac{\mathrm{c}+4 \mathrm{a}+\mathrm{d}}{6} \text {. }
$$

\section{The fuzzy distance}

Definition: Let $A=\left(a_{1}, a_{2}, a_{3} a_{4}\right), B=\left(b_{1}, b_{2}, b_{3} b_{4}\right)$ be two trapezoidal fuzzy numbers, and their Graded mean integration representation are $\mathrm{P}(\mathrm{A}), \mathrm{P}(\mathrm{B})$ respectively. Assume

$\mathrm{s}_{\mathrm{i}}=\left(\mathrm{a}_{\mathrm{i}}-\mathrm{P}(\mathrm{A})+\mathrm{b}_{\mathrm{i}}-\mathrm{P}(\mathrm{B})\right) / 2, \mathrm{i}=1,2,3,4 ;$
$\mathrm{c}_{\mathrm{i}}=|\mathrm{P}(\mathrm{A})-\mathrm{P}(\mathrm{B})|+\mathrm{s}_{\mathrm{i}}, \mathrm{i}=1,2,3,4$

then the fuzzy distance of A,B is $C=\left(c_{1}, c_{2}, c_{3} c_{4}\right)$.

Example 1:Assume A(greater or less than 3$)=(1,2,4$, $5), \mathrm{B}($ greater or less than 7$)=(5,6,8,9)$ then $\mathrm{s}_{1}=-2, \mathrm{~s}_{2}=-1, \mathrm{~s}_{3}=1 . \mathrm{s}_{4}=2$. Therefore. $\mathrm{c}_{1}=2, \mathrm{c}_{2}=3, \mathrm{c}_{3}=5, \mathrm{c}_{4}=6$; So the fuzzy distance of A, B is $\mathrm{C}=(2,3,5,6)$, We can say $\mathrm{C}$ as greater or less than 4 .

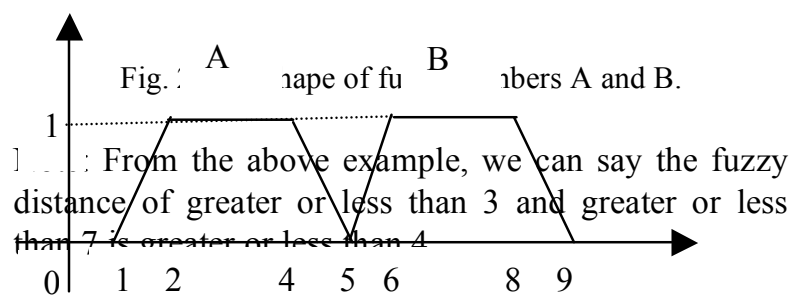

ln ge , _ $\mathrm{x}$ " be transferred to symmetry trapezoidal fuzzy number as

$\mathrm{A}=((1-\mathrm{a} \%) \mathrm{x},(1-\mathrm{b} \%) \mathrm{x},(1+\mathrm{b} \%) \mathrm{x},(1+\mathrm{a} \%) \mathrm{x})$,

Where $\mathrm{a}, \mathrm{b}$ are nonnegative real numbers and $\mathrm{a} b$..

Property 1: Let trapezoidal fuzzy number A as "greater or less than X", and B as "greater or less than y". Then the fuzzy distance of A and B is "greater or less than | $\mathrm{x}-\mathrm{y} \mid$ ".

Proof: Let

$\mathrm{A}=((1-\mathrm{a} \%) \mathrm{x},(1-\mathrm{b} \%) \mathrm{x},(1+\mathrm{b} \%),(1+\mathrm{a} \%) \mathrm{x}), \mathrm{B}=((1-\mathrm{c} \%) \mathrm{y}$, (1-d\%)y, (1+d\%)y, (1+c\%)y.)

Then the GMIR of $\mathrm{A}$ and $\mathrm{B}$ are $\mathrm{x}$ and $\mathrm{y}$.

$\mathrm{s}_{1}=((1-\mathrm{a} \%) \mathrm{x}-\mathrm{x}+(1-\mathrm{c} \%) \mathrm{y}-\mathrm{y}) / 2$ 


$$
\begin{aligned}
& =-(a \% x+c \% y) / 2, \\
\mathrm{~s}_{2} & =((1-b \%) x-x+(1-d \%) y-y) / 2 \\
& =-(b \% x+d \% y) / 2, \\
\mathrm{~S}_{3} & =((1+b \%) x-x+(1+d \%) y-y) / 2 \\
& =(b \% x+d \% y) / 2, \\
\mathrm{~S}_{4} & =((1+a \%) x-x+(1+c \%) y-y) / 2 \\
& =(a \% x+c \% y) / 2 .
\end{aligned}
$$

\section{Therefore}

$\mathrm{c}_{1}=|\mathrm{x}-\mathrm{y}|-(\mathrm{a} \% \mathrm{x}+\mathrm{c} \% \mathrm{y}) / 2$,

$\mathrm{c}_{2}=|\mathrm{x}-\mathrm{y}|-(\mathrm{b} \% \mathrm{x}+\mathrm{d} \% \mathrm{y}) / 2$,

$\mathrm{c}_{3}=|\mathrm{x}-\mathrm{y}|+(\mathrm{b} \% \mathrm{x}+\mathrm{d} \% \mathrm{y}) / 2$,

$\mathrm{c}_{4}=|\mathrm{x}-\mathrm{y}|+(\mathrm{a} \% \mathrm{x}+\mathrm{c} \% \mathrm{y}) / 2$.

Let $\mathrm{e} \%=((\mathrm{a} \% \mathrm{x}+\mathrm{c} \% \mathrm{y}) / 2) /(|\mathrm{x}-\mathrm{y}|)$,

$$
\mathrm{f} \%=((\mathrm{b} \% \mathrm{x}+\mathrm{d} \% \mathrm{y}) / 2) /(|\mathrm{x}-\mathrm{y}|) \text {. }
$$

Then $\mathrm{C}=((1-\mathrm{e} \%)|\mathrm{x}-\mathrm{y}|,(1-\mathrm{f} \%)|\mathrm{x}-\mathrm{y}|$, $(1+\mathrm{f} \%)|\mathrm{x}-\mathrm{y}|,(1+\mathrm{e} \%)|\mathrm{x}-\mathrm{y}|)$, That is greater or less than $|\mathrm{x}-\mathrm{y}|$.

Remark: The triangle fuzzy number "about $x$ " can be denote as $((1-\mathrm{a} \%) \mathrm{x}, \mathrm{x}, \mathrm{x},(1+\mathrm{a} \%) \mathrm{x})$. Then the fuzzy distance of "about $\mathrm{x}$ " and "about $\mathrm{y}$ " can be found as "about $|\mathrm{x}-\mathrm{y}|$ ".

\section{Comparison}

Generalized triangular fuzzy number $\mathrm{Y}=(\mathrm{c}, \mathrm{a}, \mathrm{d}$; w) is a special case of generalized trapezoidal fuzzy number when $b=a$. Then replacing $b$ by $a$ in formula (2), the graded mean integration representation of $\mathrm{Y}$ becomes

Now, we study some different distance measures of fuzzy numbers in [1, 4, 5, 6, 7] as follows.

In 1991, Kaufmann et al. have discussed a distance measure of fuzzy numbers as

$$
d(A, B)=\int_{0}^{1}\left(\left|a_{L}^{(\alpha)}-b_{L}^{(\alpha)}\right|+\left|a_{R}^{(\alpha)}-b_{R}^{(\alpha)}\right|\right) d \alpha,
$$

where $\left[a_{L}{ }^{(\alpha)}, a_{R}{ }^{(\alpha)}\right]$ and $\left[b_{L}{ }^{(\alpha)}, b_{R}{ }^{(\alpha)}\right]$ are the closed interval of $\alpha$-cuts of fuzzy number $\mathrm{A}$ and $\mathrm{B}$.

In 1997, Heilpern defined three distance measures as follows. First, the mean distance is

$$
\sigma(\mathrm{A}, \mathrm{B})=|\mathrm{EV}(\mathrm{A})-\mathrm{EV}(\mathrm{B})|,
$$

where $\operatorname{EV}(\mathrm{A})$ and $\operatorname{EV}(\mathrm{B})$ are the expected value of fuzzy number $\mathrm{A}$ and $\mathrm{B}$ respectively.

Second, the distance measure generated by a Minkowski distance is
$\mathrm{d}(\mathrm{A}, \mathrm{B})=\int_{0}^{1} \mathrm{~d}_{\mathrm{P}}\left(\mathrm{A}_{\mathrm{h}}, \mathrm{B}_{\mathrm{h}}\right) \mathrm{dh}$,

where $A_{h}=\left[a_{L}{ }^{(h)}, a_{R}{ }^{(h)}\right]$ and $B_{h}=\left[b_{L}{ }^{(h)}, b_{R}{ }^{(h)}\right]$ is the closed interval of h-level of fuzzy number $\mathrm{A}$ and $\mathrm{B}$, and $\mathrm{d}_{\mathrm{P}}\left(\mathrm{A}_{\mathrm{h}}, \mathrm{B}_{\mathrm{h}}\right)=$

$\left\{\begin{array}{lc}\left(0.5\left(\left|\mathrm{a}_{\mathrm{L}}{ }^{(\mathrm{h})}-\mathrm{b}_{\mathrm{L}}{ }^{(\mathrm{h})}\right|^{\mathrm{p}}+\left|\mathrm{a}_{\mathrm{R}}{ }^{(\mathrm{h})}-\mathrm{b}_{\mathrm{R}}{ }^{(\mathrm{h})}\right|^{\mathrm{p}}\right)\right)^{1 / \mathrm{p}}, & 1 \leq \mathrm{p}<\infty, \\ \max \left\{\mathrm{a}_{\mathrm{L}}{ }^{(\mathrm{h})}-\mathrm{b}_{\mathrm{L}}{ }^{(\mathrm{h})}|,| \mathrm{a}_{\mathrm{R}}{ }^{(\mathrm{h})}-\mathrm{b}_{\mathrm{R}}{ }^{(\mathrm{h})} \mid\right\}, & \mathrm{p}=\infty .\end{array}\right.$

Third, the geometrical distance between two trapezoidal fuzzy numbers is

$$
\begin{aligned}
& \delta_{\mathrm{p}}(\mathrm{C}, \mathrm{D})= \\
& \begin{cases}0.25\left(\sum_{\substack{i=1 \\
i}}^{4}\left|\mathrm{ci}-d_{\mathrm{i}}\right|^{p}\right)^{1 / p} \quad \text { for } 1 \leq \mathrm{p}<\infty, \\
\max \left(\left|\mathrm{ci}-d_{\mathrm{i}}\right|\right) & \text { for } \mathrm{p}=\infty .\end{cases}
\end{aligned}
$$

where $\mathrm{C}=\left(\mathrm{c}_{1}, \mathrm{c}_{2}, \mathrm{c}_{3}, \mathrm{c}_{4}\right)$ and $\mathrm{D}=\left(\mathrm{d}_{1}, \mathrm{~d}_{2}, \mathrm{~d}_{3}, \mathrm{~d}_{4}\right)$ are two trapezoidal fuzzy numbers.

In 1998 Chen and Hsieh have define the distance of two LR type fuzzy numbers as following:

Let $A$ and $B$ be two LR type fuzzy numbers and $\mathrm{P}(\mathrm{A}), \mathrm{P}(\mathrm{B})$ are GMIR of $\mathrm{A}$ and $\mathrm{B}$ respectively. Then the distance of $\mathrm{A}$ and $\mathrm{B}$ defined as $|\mathrm{P}(\mathrm{A})-\mathrm{P}(\mathrm{B})|$.

All of the above methods are using real numbers to calculate the distance, but this new method uses fuzzy number to measure the distance of two trapezoidal fuzzy numbers. The new method is more fixed the institute meaning. For example the distance of greater or less than 6 and greater or less than 8 is greater or less than 2 in new method. In the above methods the distance become a real number. Such as the distance use GMIR method then the distance becomes 2 .

\section{Conclusion}

In this paper, we introduce the fuzzy distance of two trapezoidal fuzzy numbers. After comparing our method with several different distance methods, we can find that our new method looks more suitable. Our new method of fuzzy distance not only can treat $n$ trapezoidal fuzzy numbers, but also do not change the results of fuzzy distance values after increase (or decrease) a trapezoidal fuzzy number into (from) original trapezoidal fuzzy numbers group. Finally, the property of fuzzy distance of greater or less than $\mathrm{x}$ is proved.

\section{References}

[1] Chieh Hsun Hsieh, and Shan Huo Chen, "Graded mean representation distance of generalized fuzzy number", Proc. of the sixth Conference on Fuzzy 
Theory and its Applications (CD ROM), filename 032.wdl, pp. 1-5, Chinese Fuzzy Systems Association, Taiwan, 1998.

[2] S. H. Chen and C. H. Hsieh, "Graded mean integration representation of generalized fuzzy number", Proc. of Conference of Taiwan Fuzzy System Association, Taiwan, 1998.

[3] Shan Huo Chen and Chih Hsun Hsieh, "Graded Mean Integration Representation of Generalized Fuzzy Number", Journal of the Chinese Fuzzy System Association, Vol. 5, No. 2, pp. 1-7, Taiwan, 1999.

[4] Shan Huo Chen and Chih Hsun Hsieh, "Representation, Ranking, Distance, and Similarity of L-R type fuzzy number and Application", Australia Journal of Intelligent Information Processing Systems, Vol. 6, No. 4, pp.217-229, Australia, 2000.

[5] S. Heilpern, "Representation and application of fuzzy numbers", Fuzzy sets and Systems 91(2): 259-268, 1997.

[6] A. Kaufmann and M. M. Gupta, Introduction to fuzzy arithmetic theory and applications, Van Nostrand Reinhold, 1991.

[7] X. Liu, "Entropy, distance measure and similarity measure of fuzzy sets and their relations", Fuzzy Sets and Systems 52(3): 305-318 (1992).

[8] L. A. Zadeh, "Fuzzy set", Information and Control 8: 338-353, 1965. 